Article

\title{
Investigation of the Effect of Plasma Polymerized Siloxane Coating for Enzyme Immobilization and Microfluidic Device Conception
}

\author{
Kalim Belhacene ${ }^{1,2}$, Adil Elagli ${ }^{1,2}$, Céline Vivien ${ }^{1}$, Anthony Treizebré ${ }^{1}$, Pascal Dhulster ${ }^{2}$, \\ Philippe Supiot ${ }^{1}$ and Renato Froidevaux ${ }^{2, *}$ \\ 1 Institut d'Electronique, de Microélectronique et de Nanotechnologie (IEMN)—UMR CNRS 8520, \\ Université Lille Nord de France-Sciences et Technologies, Villeneuve 59650, d'Ascq, France; \\ kalim.belhacene@yahoo.fr (K.B.); elagli@hotmail.fr (A.E.); celine.vivien@univ-lille1.fr (C.V.); \\ anthony.treizebre@univ-lille1.fr (A.T.); philippe.supiot@univ-lille1.fr (P.S.) \\ 2 EA 7394-ICV-Institut Charles Viollette, University of Lille, F-59000 Lille, France; \\ pascal.dhulster@univ-lille1.fr \\ * Correspondence: renato.froidevaux@univ-lille1.fr; Tel.: +33-320-41-75-66
}

Academic Editor: David D. Boehr

Received: 14 October 2016; Accepted: 9 December 2016; Published: 16 December 2016

\begin{abstract}
This paper describes the impact of a physical immobilization methodology, using plasma polymerized 1,1,3,3, tetramethyldisiloxane, on the catalytic performance of $\beta$-galactosidase from Aspergillus oryzae in a microfluidic device. The $\beta$-galactosidase was immobilized by a polymer coating grown by Plasma Enhanced Chemical Vapor Deposition (PEVCD). Combined with a microchannel patterned in the silicone, a microreactor was obtained with which the diffusion through the plasma polymerized layer and the hydrolysis of a synthetic substrate, the resorufin- $\beta$-D-galactopyranoside, were studied. A study of the efficiency of the immobilization procedure was investigated after several uses and kinetic parameters of immobilized $\beta$-galactosidase were calculated and compared with those of soluble enzyme. Simulation and a modelling approach were also initiated to understand phenomena that influenced enzyme behavior in the physical immobilization method. Thus, the catalytic performances of immobilized enzymes were directly influenced by immobilization conditions and particularly by the diffusion behavior and availability of substrate molecules in the enzyme microenvironment.
\end{abstract}

Keywords: physical immobilization; microreactor; plasma polymer; modelling; diffusion

\section{Introduction}

Microfabricated devices have been subject to high growth for the last twenty years. This technology reveals various potentials of applications for analytical tools like immunoassays, proteins [1], DNA [2] analysis, and production tools. The use of microdevices was motivated by time saving, the decrease of analyte volume or by ecological aspects like the reduction of amounts of reagents and chemicals used. Microfabrication process development allows for easily obtaining robust and commercially attractive microdevices, especially with multifunctional materials already known like silicones e.g., the PolyDimethylSiloxane (PDMS).

BioMEMS (Biological MicroElectroMechanical System) result from direct integration of biological species within the microsystem [3]. The biological function confers new possibilities of applications particularly in biochemistry, medical analysis or for clinical diagnosis [4,5]. Most of the time, the biofunctionalization was performed after microfabrication by exploiting the interaction properties of the support with biomolecules or the binding properties of linkage agents [6]. However, these kinds of immobilization processes often require numbers of preparation steps, a significant consumption of 
unfriendly chemicals, and even toxic-like spacers, to obtain a stable immobilization. To avoid most of these constraints, a physical approach like simple biomolecule adsorption could be considered but leads to poor interaction strengths and risks of enzyme leakage. For that reason, physical trapping was preferred for better physical enzyme preservation during the experiment.

Enzyme trapping in a polymer matrix was used [7-9], and, more specifically, a plasma-polymerized film [10,11], which has many advantages like biocompatibility, thermal stability, mechanical properties and is relevant for adsorption [12], linkage [13], or entrapment in a matrix [14]. Physical immobilization often induces a decrease of enzyme activity but shows a better stability of enzyme during the reaction [15]. The main objective of this work was to investigate the impact of physical immobilization of enzymes with plasma polymerized film on the enzyme catalytic behavior in a microreactor.

The coating of the enzyme was performed by plasma polymerization through Plasma Enhanced Chemical Vapor Deposition (PECVD). This method is based on partial fragmentation and recombination of a precursor, allowing the deposition of a thin polymer-film, at moderate temperature, in dry conditions. Among possible precursors, an organosilicon, e.g., the 1,1,3,3 Tetramethyldisiloxane (TMDSO), was used. The thin film deposited under remote conditions revealed a very good potential for microfabrication [16-19] and biofunctional compatibility [10,18]. Indeed, the ppTMDSO layer has shown its ability to immobilize enzymes while maintaining their activity and stability for several uses [10].

The ppTMDSO, used for enzyme immobilization, has allowed the diffusion of substrate through the matrix to reach the enzyme, its hydrolysis and the product release back to the liquid bulk, while avoiding enzyme leakage during the experiment. The $\beta$-galactosidase (denoted $\beta$-gal) was used as a model enzyme [13,20-24], and the reaction with resorufin- $\beta$-D-galactopyranoside (RBG) was chosen for its simplicity of implementation and its high sensibility by obtaining a fluorescent product (resorufin). The body of the microreactor was designed with PDMS, commonly used for its quick patterning of microfluidic channels. The methodology used was by (i) the reaction implementation, consisting of a continuous feed of RBG in the enzymatic microreactor; (ii) the determination of the kinetic parameters; and (iii) a comparison with values obtained with a "free state" enzyme. Thus, the impact of the immobilization procedure on enzyme behavior has been determined. The robustness of the immobilization procedure was also evaluated for several cycles of use. Finally, simulation using Comsol Multiphysics () software (number 1018891, version 5.1., COMSOL.AB, USA, 2015) and a kinetics-diffusion modelling approach were investigated to understand the complex diffusion-reaction mechanism occurring inside the microsystem and to extract information about substrate and product transport within the system. In the present immobilization process, the modelling of the enzyme behavior's influence on the enzyme activity constitutes a new original contribution to the understanding of enzyme catalysis involving such a membrane-like coating.

\section{Results and Discussion}

A microfluidic device preparation was represented in the Figure 1. This device was obtained using a standard photolithography and a replica molding method. The microdevice was $100 \mu \mathrm{m}$ wide, $3000 \mu \mathrm{m}$ long, $20 \mu \mathrm{m}$ high with an approximate overall surface of $0.13 \mathrm{~cm}^{2}$, including the microchannel and the reservoirs. A volume of $\beta$-galactosidase solution was deposited $(2 \mu \mathrm{L})$ on a glass slide and spread as circular spot of $1 \mathrm{~cm}$ diameter followed by a coating with a $1 \mu \mathrm{m}$-thick ppTMDSO layer deposited by the RPECVD process. After enzyme coating, a PDMS bloc including a microchannel was stuck on this layer after a Corona treatment [25]. Corona treatment had allowed an activation of the surface with pine air electric discharges at atmospheric pressure. This treatment increased the surface energy and also favored adhesion between the treated area and another surface [26]. Silica capillaries were connected to reservoirs and glued to avoid leaks of liquids. Three washes with $1 \mathrm{~mL}$ of distilled water were realized in the microsystem with a syringe pump, at $10 \mu \mathrm{L} / \mathrm{min}$, to remove non immobilized enzymes. The estimated enzyme leakage amount during this step was around $10 \%$ of the initial quantity of enzyme deposited $(\sim 1 \mu \mathrm{g})$. Thereafter, RBG substrate solution was injected into the microsystem for enzymatic reaction. 

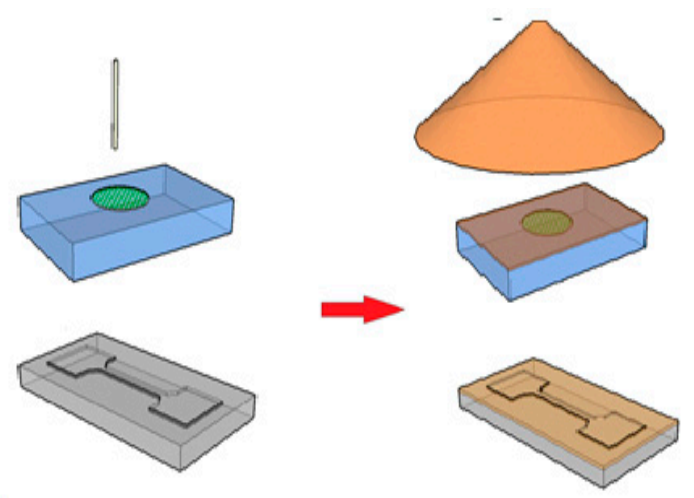

B)

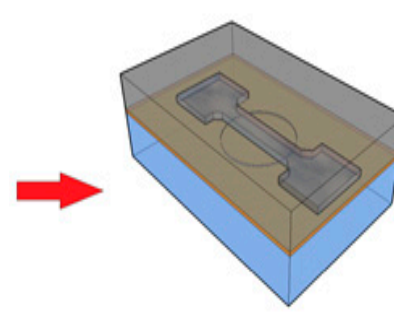

D)

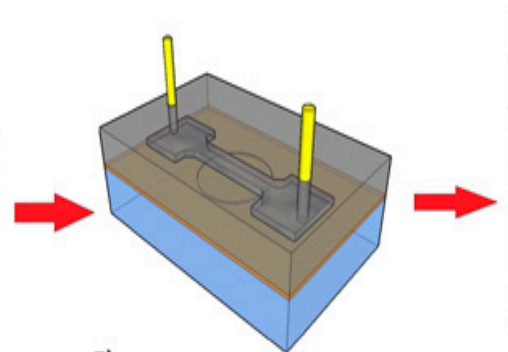

E)

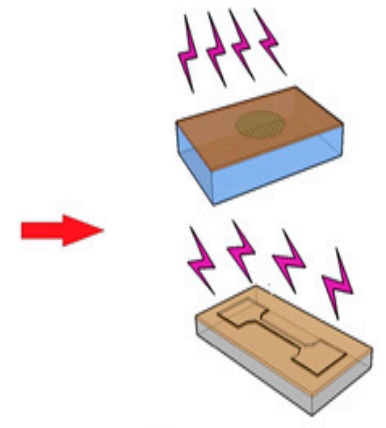

C)

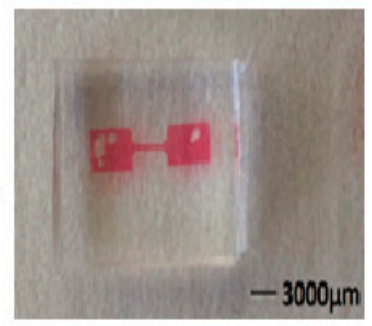

F)

Figure 1. Conception of PDMS (PolyDimethylSiloxane) microsystem including immobilized enzyme by plasma polymer deposition. $\beta$-galactosidase was deposited with micropipette on a glass slide (A) and overcoated by $1 \mu \mathrm{m}$ of ppTMDSO (plasma polymerized tetramethyldisiloxane) (B), and the microchannel was also covered by $500 \mathrm{~nm}$ of ppTMDSO and post treated by $\mathrm{N}_{2} / \mathrm{O}_{2}$ plasma to obtain a glass-like surface. Both elements were treated by Corona discharge to activate the surface $(\mathbf{C})$ prior their bonding (D). Finally, capillaries were added to allow the fluid circulation (E). The picture (F) shows the final microchannel obtained.

\subsection{Stability of the Immobilized $\beta$-Gal}

To evaluate the influence of the immobilization methodology on the $\beta$-gal stability, several reaction runs were realized with the same flow rate and the same substrate concentration. Figure 2 shows the enzymatic activity ( $\mu \mathrm{mol} / \mathrm{min}$ ) evolution calculated for an initial RBG concentration of $100 \mu \mathrm{M}$ and a flow rate of $10 \mu \mathrm{L} / \mathrm{min}$. For each run, 10 fractions of $100 \mu \mathrm{L}$ of solution were collected every $10 \mathrm{~min}$, and measured with the spectrofluorometer. After each test, the microsystem was washed with distilled water at $10 \mu \mathrm{L} / \mathrm{min}$ flow rate for $60 \mathrm{~min}$. Then, the enzymatic activity was calculated in each fraction considering the final volume of solution collected and the corresponding time. The results obtained were summarized in the Figure 2 for five consecutive runs in the same microreactor. The experiment was realized in three identical microreactors in the same conditions ( $\mathrm{RBG}_{0}$ concentration, flow rate).

For each run, a progressive increase of the enzymatic activity was observed until the 3rd-4th fraction, where the activity becomes steady Moreover, the first two runs (called "tests 1 and 2") showed a difference of activity with the three other runs ("tests 3-5"). Finally, the steady-state phase demonstrated a stability of the reaction inside the microsystem, suggesting that a time was necessary for obtaining a stable catalytic reaction. 


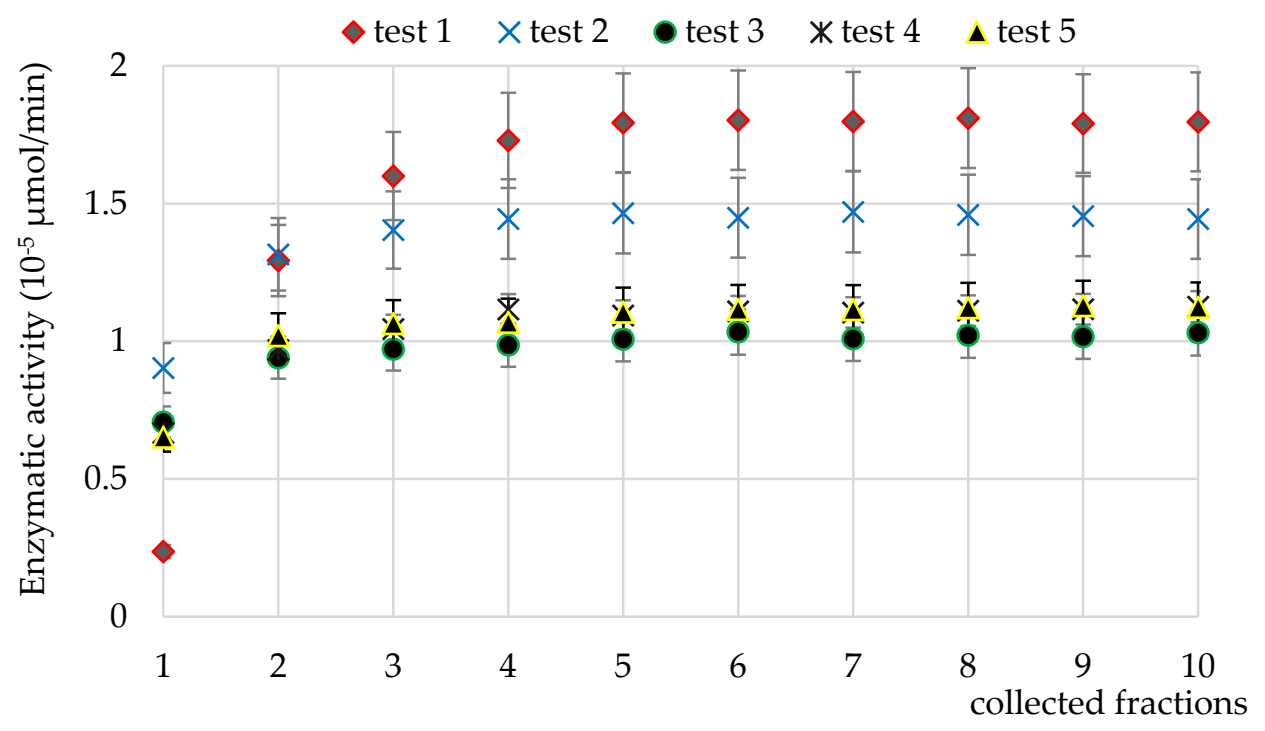

Figure 2. Enzymatic activity calculated for $100 \mu \mathrm{M}$ of RBG (Resorufin $\beta$ Galactopyranoside) injected at a flow rate of $10 \mu \mathrm{L} / \mathrm{min}$ in the microsystem, and measured in collected fractions, for five consecutive runs of activity. Resorufin concentrations were measured at the outlet of the microsystem, in the collected fractions, with a spectrofluorometer at $590 \mathrm{~nm}$ and converted to enzymatic activity. The microsystem was washed by distillated water between each run.

A decrease of only $40 \%$ of the enzymatic activity was observed after three runs, followed by good stability in the subsequent runs. The variation could be explained by (i) a reorganization of $\beta$-gal in the polymer network during the flow of water with solutes, consisting of a partial solubilization and diffusion inside the polymer, either hindering their movement or leading to an inactive position or their release to the bulk; and (ii) a ppTMDSO fouling with substrate and/or product molecules, a phenomenon also observed in all separation process using membranes [27]. Experimentally, an accumulation of these molecules may occur, favoring the steady-state phase but leading to a decrease of the enzymatic activity. This accumulation could also limit transport of molecules from the bulk to the enzyme and vice versa. However, these two phenomena seem to have a limited impact on the enzymatic activity in the microsystem.

\subsection{Kinetic Parameters of Immobilized $\beta$-Gal}

Enzymatic activity evolution was represented by the classical Michaelis-Menten Equation (1) [13,22] and is represented in Figure 3. Then, kinetics parameters were determined using the Lineweaver-Burk representation for the immobilized and free enzyme (Figure 3).

$$
V=V_{\max } \cdot \frac{[S]}{K_{m}+[S]}
$$

Different RBG substrate concentrations $(5,10,20,50,100 \mu \mathrm{M})$ were used to determine $\beta$-gal kinetic parameters. Concerning free enzymes, $V_{\max }=51.7 \pm 11 \times 10^{-3} \mu \mathrm{mol} / \mathrm{min}$ and $K_{\mathrm{m}}=453 \pm 103 \mu \mathrm{M}$. The $K_{\mathrm{m}}$ value was reasonably close to those mentioned in the literature for similar catalytic conditions in microreactors with $\beta$-gal immobilized on beads [28]. For immobilized enzymes, $V_{\max }=0.57 \pm 0.07 \times 10^{-3} \mu \mathrm{mol} / \mathrm{min}$ and $K_{\text {mapp }}=511 \pm 112 \mu \mathrm{M}$. The apparent $K_{\mathrm{m}}\left(K_{\mathrm{mapp}}\right)$ value was substantially close to that of $K_{\mathrm{m}}$ obtained with free $\beta$-gal, while $V_{\max }$ values showed a large discrepancy. This latter difference could be explained by the quantity of $\beta$-gal involved during the reaction. Indeed, in free conditions, $10 \mu \mathrm{g}$ of enzyme were homogeneously mixed in RBG solution and were totally available for reaction, unlike immobilized conditions. Thus, considering the surface of the microchannel where the reaction occurred $\left(0.13 \mathrm{~cm}^{2}\right)$ and assuming 
a homogenous enzyme distribution on this surface $\left(7.64 \mu \mathrm{g} / \mathrm{cm}^{2}\right), 1 \mu \mathrm{g}$ of enzymes were available for the reaction. Moreover, the calculation of the specific enzymatic activity values $(V \max )_{\text {spe, }}$, which depends on the enzyme quantity, led to a ratio value of $8.6\left(\left(V_{\max }\right)_{\text {spe }} \cong 5.2 \mu \mathrm{mol} / \mathrm{min} / \mathrm{mg}\right.$ enzyme for free $\beta$-gal, while $\left(V_{\max }\right)_{\text {spe }}$ for immobilized $\beta$-gal $\cong 0.6 \mu \mathrm{mol} / \mathrm{min} / \mathrm{mg}$ enzyme). This difference between free and immobilized conditions was already considered in a previous work [10], for the similar conditions where the influence of $\beta$-gal immobilization in ppTMDSO with another substrate, and the o-nitrophenyl- $\beta$-D-galactopyranoside was compared with free enzyme $\left(\left(V_{\max }\right)_{\text {spe }}\right.$ for free $\beta$-gal $\cong 9.83 \mu \mathrm{mol} / \mathrm{min} / \mathrm{mg}$ enzyme $/ /\left(V_{\text {max }}\right)_{\text {spe }}$ for immobilized $\beta$-gal $\cong 1.52 \mu \mathrm{mol} / \mathrm{min} / \mathrm{mg}$ enzyme). The values of $K_{\text {cat }}$ and of the catalytic efficiency factor $K_{\text {cat }} / K_{\mathrm{m}}$ were within a ratio close to 10 (see Table 1), showing the significant impact of the immobilization process by physical trapping on the enzymatic activity of $\beta$-gal. These values were the results of the availability of the enzyme for reaction at the start of the experiment, and the protein conformational changes induced by the support, the steric hindrances, and diffusional effects as shown in the work of Gulec et al. for the $\beta$-galactosidase onto resin [23] or inside beads [29]. Since it was difficult to access the enzyme microenvironment inside the microsystem, the modeling of physical phenomena occurring at a microscale could provide more information about the catalytic behavior of immobilized enzyme.
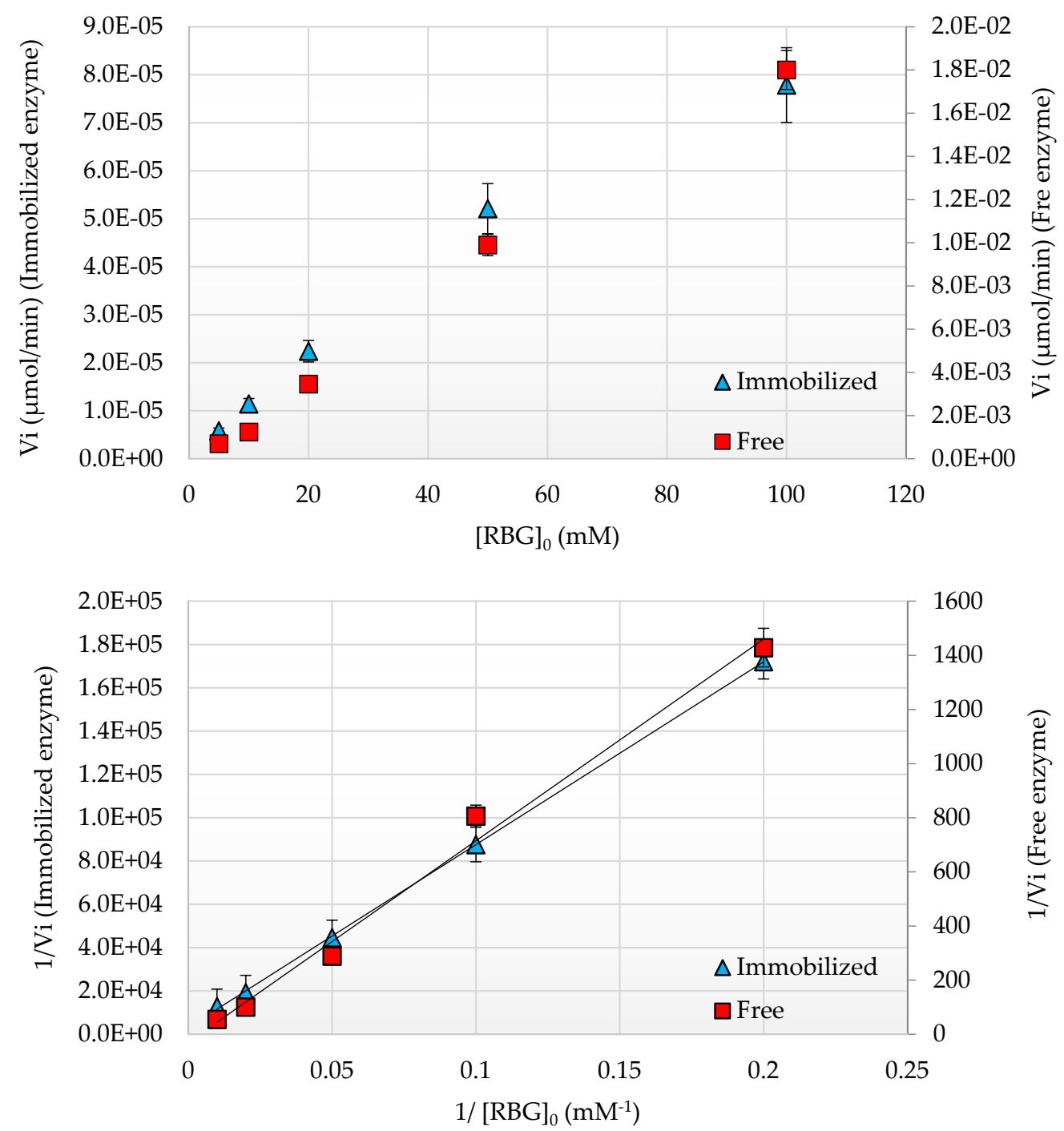

Figure 3. Michaelis-Menten (a) and Lineweaver-Burk (b) representation of enzymatic activity obtained for immobilized (triangles) and free (squares) enzyme for different initial substrate (RBG) concentrations. 
Table 1. Kinetics parameters of free and immobilized $\beta$-galactosidase. These parameters were calculated using the Lineweaver-Burk representation.

\begin{tabular}{|c|c|c|c|c|c|}
\hline $\begin{array}{l}\text { Catalytic } \\
\text { Constants }\end{array}$ & $K_{\mathrm{m}}(\mu \mathrm{M})$ & $\begin{array}{c}V_{\max } \\
\left(10^{-3} \mu \mathrm{mol} \cdot \min ^{-1}\right)\end{array}$ & $\begin{array}{c}V_{\text {maxspé }} \\
\left(\mu \mathrm{mol} \cdot \mathrm{min}^{-1} \cdot \mathrm{mg}^{-2}\right)\end{array}$ & $K_{\text {cat }}\left(\mathrm{s}^{-1}\right)$ & $\begin{array}{c}K_{\text {cat }} / K_{\mathrm{m}} \\
\left(\mu \mathrm{M}^{-1} \cdot \mathrm{s}^{-1}\right)\end{array}$ \\
\hline $\begin{array}{c}\text { Free } \\
\beta \text {-galactosidase }\end{array}$ & $453 \pm 130$ & $52 \pm 11$ & 5.2 & 9.0 & 0.022 \\
\hline $\begin{array}{c}\text { Immobilized } \\
\beta \text {-galactosidase }\end{array}$ & $511 \pm 112$ & $0.57 \pm 0.07$ & 0.6 & 1.0 & 0.002 \\
\hline
\end{tabular}

\subsection{Modeling of Physical Phenomena inside the Microsystem}

To understand the catalytic behavior of immobilized enzyme under the polymer, diffusion phenomena of molecules (substrates and products) inside the microreactor were modelled using COMSOL Multiphysics (c) 5.2 software (number 1018891, version 5.1., COMSOL.AB, USA, 2015). This software was mainly used to model heat transfer, gas or fluid diffusion. The design of the microsystem was modeled in two dimensions (Figure 4). The modelling included dimensions (3000 $\mu \mathrm{m}$ length, $20 \mu \mathrm{m}$ height, $0.3 \mathrm{~mm}^{2}$ surface) of the microchannel, the polymer thickness ( $1 \mu \mathrm{m}$ as considered as a porous polymer), the enzyme layer thickness $(0.5 \mu \mathrm{m})$, and the average flow velocity $(0.042 \mathrm{~m} / \mathrm{s})$.

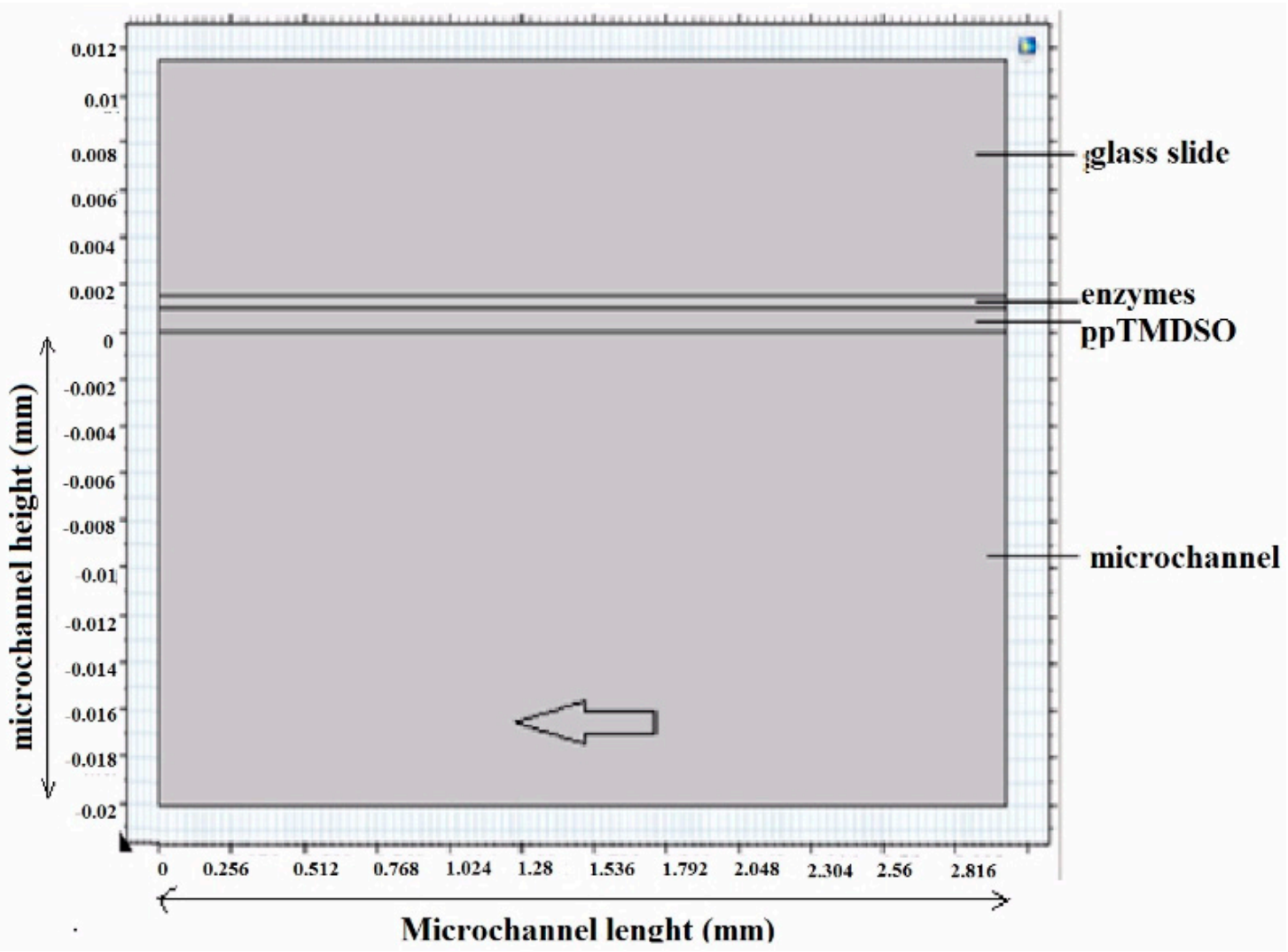

Figure 4. Two-dimensional COMSOL Multiphysics () (number 1018891, version 5.1., COMSOL.AB, USA, 2015) representation of microsystem characteristics used for modeling (the arrow indicates the flow direction).

The modeling should provide better knowledge on the flow properties. Then, solving the diffusion-reaction equation also helps to follow the spatial behavior of both substrate and product molecules. The Reynolds number was calculated using Formula (2) with $U$ being the flow rate $(\mathrm{m} / \mathrm{s})$, 
$L$ the characteristic linear dimension of our system $(\mathrm{m})$, and $v$ the kinematic viscosity of the fluid (water at $\left.25^{\circ} \mathrm{C}\right)\left(\mathrm{m}^{2} / \mathrm{s}\right)$ :

$$
\operatorname{Re}=\frac{U L}{v}
$$

Using these operational parameters, a Reynolds number of 2.8 was obtained corresponding to the Stockes regime, where the viscosity forces were predominant, particularly at the microchannel walls, where the flowing forces were negligible, supporting the hypothesis of a molecular transport by diffusion [30].

Figure 5 shows the 2D modeling of the flow velocity fields inside the microsystem in a situation close to our experimental conditions. A laminar flow was observed inside the microsystem with a maximal velocity at the center of the channel to reach a value equal to zero at the walls, where the polymer and the enzyme were located. The molecular transport by passive diffusion could then be characterized on the basis of effective velocity gradients at the right angle of the walls.

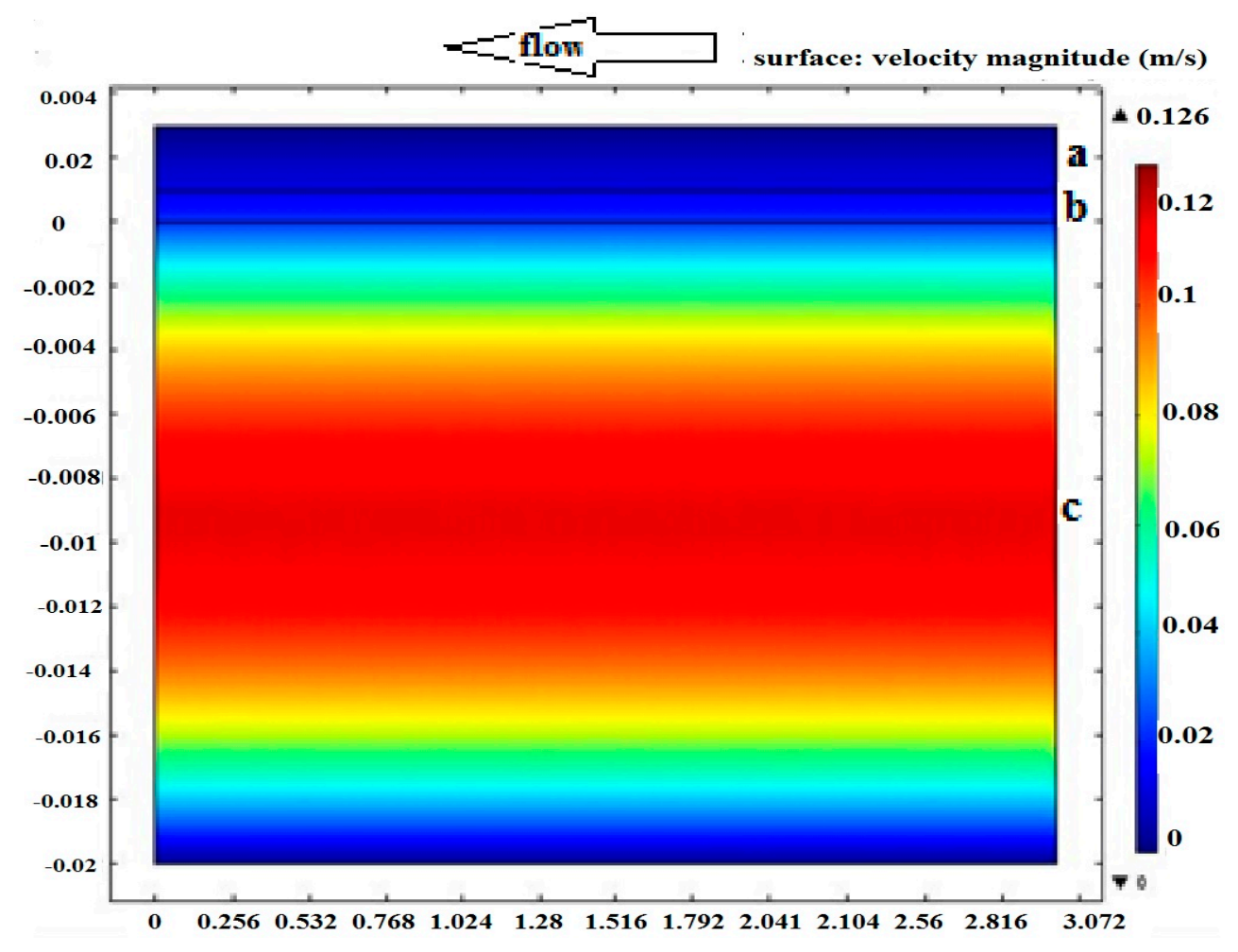

Figure 5. 2D representation by COMSOL Multiphysics (c) 5.2 software of flow velocity fields inside the microfluidic device ((a) enzyme film; (b) ppTMDSO film; (c) bulk). The flow direction was indicated by the arrow.

Then, a molecular diffusion modeling was achieved for substrates and products inside the microsystem (Figure 6). The modeling has allowed a flow and diffusion transports representation, and a better understanding of the dynamics of the enzymatic kinetics. The enzyme quantity was neglected and the reactional model S $+\mathrm{E} \rightarrow \mathrm{P}$ (Substrate + Enzyme $\rightarrow$ Product) was considered with a catalytic constant of $k=8 \mathrm{~s}^{-1}$ (near to the $k_{\text {cat }}$ value for free enzyme). A substrate concentration of $100 \mu \mathrm{M}$ (in water) was also considered with a flow velocity $V=0.042 \mathrm{~m} / \mathrm{s}$. 

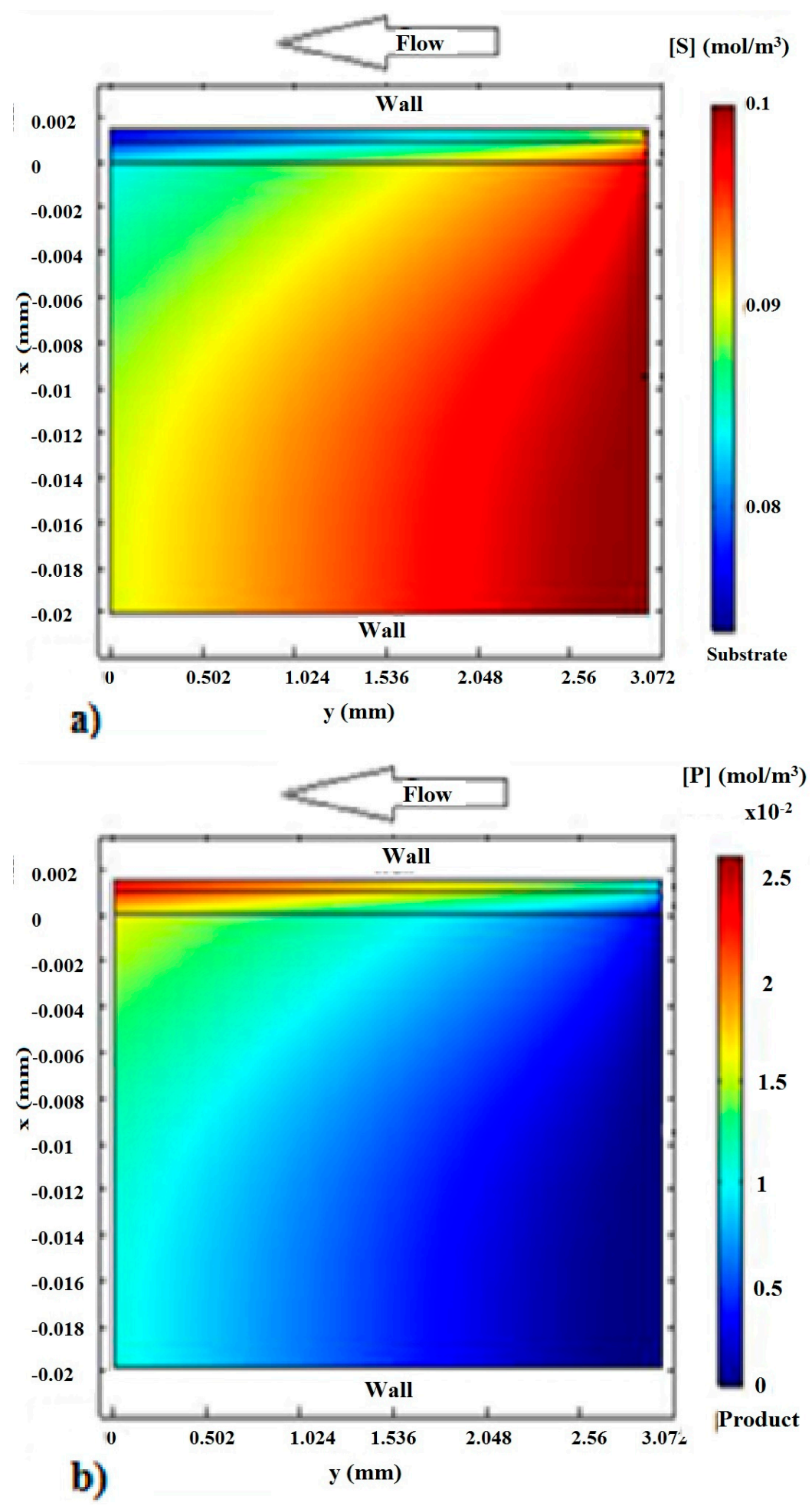

Figure 6. 2D modelling on COMSOL Multiphysics (C) 5.2 software of substrate (a) and product (b) concentration distributions inside the microfluidic device.

A non-homogeneous distribution of concentrations was observed. For substrate spatial evolution, the simulation has revealed a progressive decrease of its concentration within the bulk along the flow ( $10 \%$ of the initial concentration). In the polymer and inside the enzyme layer, the substrate concentration follows the decrease observed in the bulk. A diffusion gradient of substrate molecules from the bulk to the enzyme film was found. Indeed, a maximal substrate concentration was logically 
observed at the entry of the microchannel and also favored the strong diffusion through the polymer film to reach the enzyme compartment. Next, the substrate concentration decreased, inducing a collapse of the diffusion gradient to the polymer film and enzyme layer. This phenomenon was easily observed through the simulation near the end of microchannel (blue in Figure 6a). Concerning product spatial evolution, the reverse phenomenon was observed, with a progressive increase of concentrations in the microchannel bulk, translating the reaction between enzyme and substrate. However, near the end of the microchannel, an increase of product concentration in the polymer compartment was observed, reflecting a trapping in the polymer. This phenomenon could be explained by the diffusion gradient from enzyme layer to the bulk. Indeed, at the microchannel entry, the product concentration in the bulk was equal to zero and therefore favored its diffusion from the enzyme layer. Moreover, the product concentration increased in the bulk along the flow, limiting the product diffusion gradient, and also causing a partial accumulation in the polymer (red in Figure 6b). Thus, these phenomena could explain the catalytic activity decreasing observed during the experimental Section 2.3 caused by (i) a decrease of the amount of substrate available for enzyme (Figure 6a) and (ii) a product trapping in the polymer volume limiting leakage to the bulk (Figure 6b). To resolve these diffusion constraints, an optimization of the initial substrate concentration (promoting the substrate diffusion) and of the flow rate (for product diffusion in the bulk) seem to be necessary to limit the impact observed in each part of the microsystem.

\subsection{Diffusion inside the Microsystem}

The 2D modeling of flow velocity distribution (Figure 5) revealed a decrease of velocity near the walls. In this model, the thickness of the boundary layer $L$ to the solid surface to be of the order of $1 \mu \mathrm{m}$ was assumed. The hydrodynamic diameters of both RBG substrate and resorufin were close to $1 \mathrm{~nm}$ ( 0.8 and $0.9 \mathrm{~nm}$ respectively, calculated from the Stokes-Einstein relationship and values of diffusion coefficient in water: $D_{\mathrm{RBG}}=4.3 \times 10^{-10} \mathrm{~m}^{2} / \mathrm{s}$ and $D_{\mathrm{RBG}}=4.8 \times 10^{-10} \mathrm{~m}^{2} / \mathrm{s}$, respectively [31,32], while that of $\beta$-gal was about $16 \mathrm{~nm}\left(D_{\beta \text {-gal }}=2.7 \times 10^{-11} \mathrm{~m}^{2} / \mathrm{s}\right)$. Moreover, considering that both substrate and product had a similar mobility and diffused through the polymer, the porosity was considered in the range of 1-16 nm. Using the diffusion coefficient definition [33,34], the diffusion duration $\tau$ of RBG and resorufin through the boundary layer was calculated with Equation (3) ( $D_{\mathrm{RBG}}$ and $D_{\text {resorufin }}$ were considered as equivalent):

$$
\frac{1}{\tau}=\frac{D}{L^{2}}
$$

Thus, substrate and product molecules need about $2 \mathrm{~ms}$ to cross the boundary layer before reaching the surface of polymer.

Kinetics modeling through Equation (4) was achieved, and the results were compared with experimental values obtained with $\phi$, the substrate surface flow $\left(\mathrm{mol} / \mathrm{s} \cdot \mathrm{m}^{2}\right), S_{0}$, the initial substrate concentration $\left(\mathrm{mol} / \mathrm{m}^{3}\right), S$, the substrate concentration at the interface ppTMDSO/enzyme $\left(\mathrm{mol} / \mathrm{m}^{3}\right)$, $\phi_{\max }$ (experimental value), the maximal substrate surface flow $\left(0.75 \mu \mathrm{mol} / \mathrm{s} \cdot \mathrm{m}^{2}\right)$, and $K_{\mathrm{m}}$ (experimental value) the Michaelis constant $\left(5.11 \times 10^{-7} \mathrm{~mol} / \mathrm{m}^{3}\right)$ :

$$
\phi=\phi_{\max } \cdot \frac{[S]}{K_{m}+[S]}
$$

Figure 7 shows an Eadie-Hofstee-like representation of $\phi$ with a semi-logarithmic form with different values of $\phi /\left[S_{0}\right](\mathrm{m} / \mathrm{s})$. 


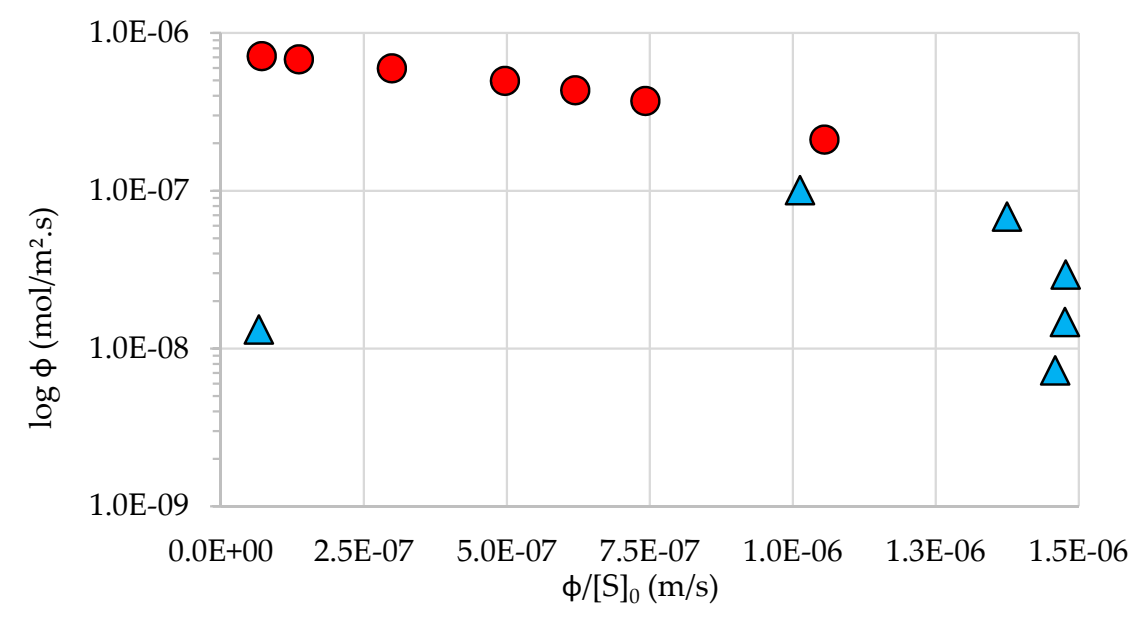

Figure 7. Semi-logarithmic Eadie-Hofstie representation of reaction equations for experimental values (blue triangles) and modelled value (red rings).

A very good correlation between experimental and model values was obtained for high values of $\phi /\left[S_{0}\right]$. However, when the substrate concentration increased (more than $100 \mu \mathrm{M}$ ), the experimental values had shown a strong discrepancy with those of the model, suggesting a direct impact of high initial concentration of substrate on the catalytic reaction. This deviation was interpreted by using the transport coefficient, $h\left(\mathrm{~m} \cdot \mathrm{s}^{-1}\right)$, of substrate and product molecules (considered as the same regarding the similar diffusion coefficient values). When the system has reached a steady-state of reaction, the diffusion flow of molecules was equal to the reaction velocity, translated by the equality between the diffusion and the kinetics Equation (5) involving the transport coefficient $h$ [35]:

$$
\phi=h\left(S_{0}-S\right)=\phi_{\max } \cdot \frac{[S]}{K_{m}+[S]}
$$

Transport coefficient was calculated for each substrate concentration (Figure 8) and revealed an important fall (over 1000 fold) for substrate concentrations up to $100 \mu \mathrm{M}$. The main effect was probably the fouling of polymer with high substrate concentration. This fouling could logically explain the difference between the experiment and model results, i.e., the decrease of substrate quantity available for the enzymatic reaction and thus the decrease of catalytic values. For low values of substrate concentration (under $100 \mu \mathrm{M}$ ), the catalytic reaction did not seem to be affected and were in agreement with the model.

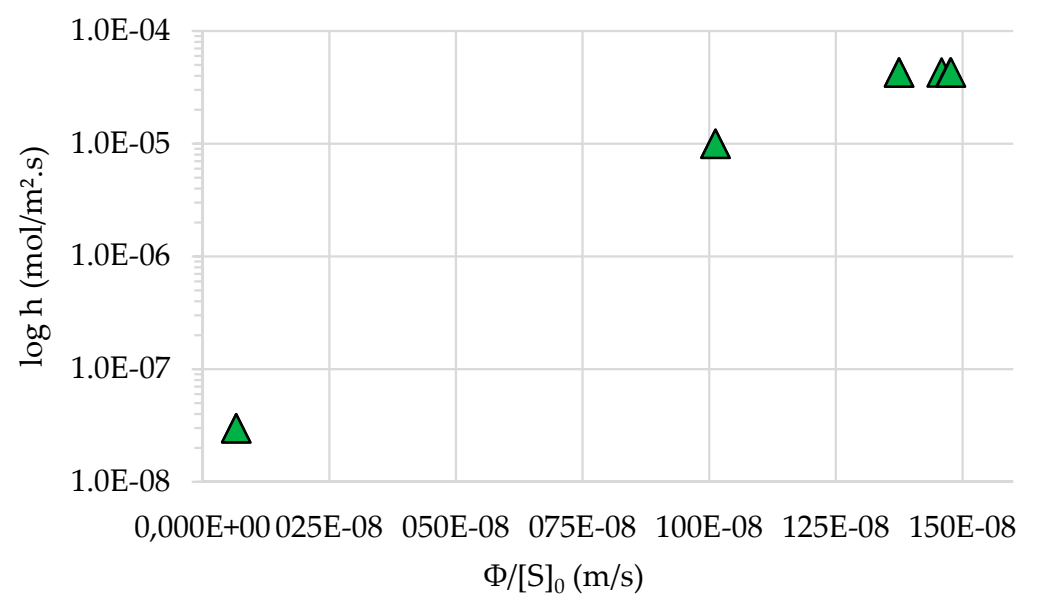

Figure 8. Semi logarithmic representation of experimental calculated transport coefficients $h$ as function of $\phi /\left[S_{0}\right]$. 
Finally, from the transport coefficient value $\left(h=4.3 \times 10^{-5} \mathrm{~m} / \mathrm{s}\right)$ for the non-fouled polymer, the diffusion coefficient of molecules through the ppTMDSO film (thickness $\mathrm{L}_{\mathrm{ppTMDSO}}=1 \mu \mathrm{m}$ ) was calculated using Relation (6):

$$
h=\frac{D_{p p T M D S O}}{L_{p p T M D S O}} \rightarrow D_{p p T M D O}=h * L_{p p T M D S O}
$$

Thus, the diffusion coefficient through the non-fouled ppTMDSO for substrate and product (considered with the same value) was $D_{\text {ppTMDSO }}=4.3 \times 10^{-11} \mathrm{~m}^{2} / \mathrm{s}$. Using Relation (3), a value of $23 \mathrm{~ms}$ was deduced for the average molecule diffusion time. It is more than 10-fold the time necessary to cross the boundary layer of similar thickness. This large difference highlights the diffusional constraints and thus qualitatively explains the variation of kinetic parameters observed in the experimental studies. The limited enzyme accessibility could mainly come from the diffusional barrier created by the polymer film itself and its potential fouling at high substrate concentrations. Optimization of the ppTMDSO thickness could reduce the diffusion time, providing the polymer maintains the enzyme trapping.

\section{Experimental Section and Methods}

\subsection{Chemicals}

The $\beta$-galactosidase ( $\beta$-D-galactoside galactohydrolase, MW: $105 \mathrm{kDa}$ ) ( $\beta$-gal) from Aspergillus oryzae was purchased from Sigma-Aldrich Chemical Co, Steinheim am Albuch, Germany. The resorufin- $\beta$-D-galactopyranoside ( $\mathrm{RBG}, \mathrm{C}_{18} \mathrm{H}_{17} \mathrm{NO}, \mathrm{MW}: 375.33 \mathrm{~g} / \mathrm{mol}$ ), a synthetic $\beta$-gal substrate purchased from Sigma-Aldrich Chemical Co., Darmstadt, Germany, was employed to evaluate the enzymatic activity during the experiment. The RBG was prepared in water and mixed, after reaction, with a basic solution of $\mathrm{Na}_{2} \mathrm{CO}_{3} 1 \mathrm{M}$ to stop the reaction and reveal the fluorescence for spectrofluorometric measurements. All aqueous solutions were prepared in Milli-Q pure deionized water (Millipore, Molsheim, France) with a resistivity of $18.2 \mathrm{~m} \Omega \cdot \mathrm{cm}$.

In addition, 1,1,3,3, tetramethyldisiloxane (TMDSO, MW: $124.33 \mathrm{~g} / \mathrm{mol}, 97 \%$ grade), purchased from Sigma Aldrich Chemical Co., Steinheim am Albuch, Germany, was used as a precursor (liquid monomer) for plasma assisted polymerization. Immobilization experiments were carried out on glass slides degreased by ultrasonicating in acetone and ethanol baths for $5 \mathrm{~min}$ each, and then dried under nitrogen stream and dehydrated at $200{ }^{\circ} \mathrm{C}$ in air during $10 \mathrm{~min}$.

The PDMS (PolyDiMethylSiloxane) kit was purchased from Sigma Aldrich Chemical Co., Steinheim am Albuch, Germany, and contained Sylgard 184 elastomer composed of pre-polymer and curing agent. These two compounds were mixed (10/1 w/w, respectively) to obtain a gel that solidifies at $80^{\circ} \mathrm{C}$ over $1 \mathrm{~h}$, enough for patterning of the microchannel. The mold used to obtain the microchannel on PDMS was made on a silicon wafer (Silitronix, Archamps, France) on which microchannels were patterned with positive photoresist resin (AZ9260) (Microchemical GmbH, Ulm, Germany).

\subsection{Plasma Polymer Deposition}

The ppTMDSO films were prepared by "cold" RPECVD in the afterglow of nitrogen microwave plasma ( $\mathrm{N}_{2}$ (Alphagaz, Villeneuve d'Ascq, France, purity grade of 99,999\%) flow rate of 1.8 standard liter-per-minute), which typical operation conditions previously described [36]. A flow of vapor precursor (TMDSO monomer) was pumped from the liquid reservoir and set by a mass flow controller to obtain $15 \mathrm{sccm}$, admixed with 25 standard cubic centimeter-per-minute (sccm) $\mathrm{O}_{2}$ (Praxair-France, purity grade of $99.999 \%$ ) gas and injected in the plasma afterglow by a tubular injector placed at $27 \mathrm{~cm}$ from a glass substrate. The monomer contains $\mathrm{Si}-\mathrm{O}-\mathrm{Si}$ bridges required to grow a polysiloxane-like structure. The $\mathrm{N}_{2}$ glow-discharge (coaxial coupling device, $2450 \mathrm{MHz}, 200 \mathrm{~W}$ ) generates $\mathrm{N}$ active atoms flowing to the late afterglow where the deposition takes place under a total pressure measured by a capacitive gauge (Pfeiffer Co, Annecy, France) and set at $5 \mathrm{mBar}$. Decomposition of the monomer in the reaction cone leads to its partial polymerization and film growth on the surface facing the flow. 
Concerning the deposition procedure, the sample was then put on the substrate holder under vacuum, pretreated in nitrogen plasma afterglow for $5 \mathrm{~min}$. Therefore, premixed oxygen and precursor were added in this afterglow for the polymer deposition step, whose duration depends on the desired thickness. Typically, $500 \mathrm{~nm}$ per minute were deposited. At last, the reactor was reset to the atmospheric pressure to get the sample back.

\subsection{Enzyme Immobilization by Entrapment}

Two microliters of $\beta$-gal solution ( $\geq 8$ units $/ \mathrm{mg}$ ) in absolute ethanol $(3 \mathrm{mg} / \mathrm{mL}$ ) were deposited on a glass slide and left until complete evaporation of the ethanol. Enzymes were preferentially prepared in ethanol because previous experiments showed a poor adhesion of the ppTMDSO on moistened surface [10], leading to avoid water for the enzyme formulation. Ethanol has no significant impact on the enzymatic activity after re-solubilization of enzyme deposited with ethanol. After ethanol evaporation, the sample was put in the plasma reactor for overcoating by ppTMDSO film. The softness of the plasma deposition conditions (quasi-room temperature, reduced pressure, short treatment duration) allowed preserving the enzyme activity [10]. Finally, the sample was washed three times with water in order to eliminate non immobilized enzyme and was kept dry at room temperature.

\subsection{Conception of Microreactor with Immobilized Enzyme}

In order to evaluate the performance of the immobilization process at microfluidic scale, the microchannel was designed from PDMS material widely used for microdevice fabrication [28,37]. A simple channel configuration was chosen, where the enzyme was immobilized, while allowing the injection of the substrate at the inlet and the collect of product at the outlet (Figure 1). Before bonding with the glass slide, the PDMS microchannels were washed in ethanol bath for 3 min and dried with nitrogen flow. Then, to avoid diffusion of biomolecules in the PDMS volume [38], the inside face of the microchannel was coated by a $500 \mathrm{~nm}$ thick ppTMDSO layer post-treated in a $\mathrm{N}_{2} / \mathrm{O}_{2}$ plasma afterglow to generate a $\mathrm{SiO}_{x}$ barrier $[39,40]$. The facing surfaces of the patterned PDMS and glass slide with immobilized enzyme (Section 2.3) by ppTMDSO were treated by the Corona process [26] for $1 \mathrm{~min}$. Then, both treated faces were brought into contact for bonding to obtain a closed microchannel. Finally, silica capillaries with $75 \mu \mathrm{m}$ inner diameter were connected to PDMS reservoirs for substrate feeding and product outflow (Figure 1).

\subsection{Enzymatic Kinetic Assays}

Enzymatic activity of $\beta$-gal was investigated with the resorufin- $\beta$-D-galactopyranoside (RBG), a fluorogenic substrate, which was hydrolyzed in galactose and resorufin molecules. The fluorescence intensity of the resorufin in solution was recorded by a Perkin-Elmer Luminescence spectrofluorometer LS50B (Perkin Elmer Company, Germany). Excitation and emission wavelengths were fixed at $571 \mathrm{~nm}$ and $590 \mathrm{~nm}$, respectively.

Experiments consisted of continuous injection of substrate solution (RBG in Milli-Q water), with a syringe pump (New Era Pump System Inc., Farmingdale, NY, USA) at controlled flow (10 $\mu \mathrm{L} / \mathrm{min})$, in the microchannel containing immobilized enzyme. Several fractions of $100 \mu \mathrm{L}$ were collected at the microchannel outlet and mixed with $50 \mu \mathrm{L}$ of a basic sodium carbonate solution $1 \mathrm{M}$, in order to stop the reaction out the device. Fluorescence intensities of samples were measured and compared with a set of resorufin solutions of known concentrations to determine the product concentration in samples.

Product concentrations were quantified for various RBG concentrations and catalytic constants were calculated using the Michaelis-Menten equation and Lineweaver-Burk representation for kinetic parameters determination.

\subsection{Modeling of Diffusional Phenomena}

Simulation with COMSOL Mulitphysics@ 5.1 software was undertaken to understand the physical phenomena inside the microsystem occurring during the experimentation. The design 
of the microchannel consisted of a glass slide, an enzyme layer, a ppTMDSO layer and the channel containing substrate solution. Substrate and product diffusion transport was modeled. Using the Stockes-Einstein relationship, the diffusion parameters for transport of these molecules within the the static bulk solution and through the PpTMDSO layer were calculated. These calculations allowed for evaluating the diffusion time of compounds in each part of the microsystem and assessing the influence of the immobilization process on the enzymatic efficiency.

\section{Conclusions}

The coupling of the microfabrication process and enzyme immobilization by plasma polymer deposition was realized successfully to obtain a microfluidic device able to hydrolyze molecules. The deposited film has allowed for efficiently retaining $\beta$-galactosidase while keeping it active for several cycles of use. The study of the kinetic parameters of immobilized enzyme revealed an important impact of the physical immobilization process on the enzymatic activity, particularly reflected on the $V_{\max }$ value. Modeling with COMSOL Multiphysics (C) allowed qualitative understanding of the diffusional constraints influence due to ppTMDSO films. A simple kinetic-diffusion model led to a rough determination of the diffusion time of both the substrate and product and also highlighted the polymer fouling at high substrate concentrations. Diffusional constraints of substrates and products through polymers were high at the beginning of experiments but tended to decrease under continuous flow conditions to finally obtain a stable and continuous production of resorufin. This original approach has allowed the understanding of the operational catalytic behavior of the immobilized enzyme, using physical-chemical modelling. This study has also stressed the difficulty to fully control the phenomena occurring in the microenvironment of the enzyme at this stage of the work.

Acknowledgments: We are grateful to Christian Malas for his help in RPECVD experiments and Kevin Robert for PDMS and microstructure conception.

Author Contributions: Kalim Belhacene, Adil Elagli, Celine Vivien, Anthony Treizebre, Philippe Supiot and Renato Froidevaux conceived and designed the experiments; Kalim Belhacene, Adil Elagli, Celine Vivien, Anthony Treizebre, Renato Froidevaux and Philippe Supiot performed the experiments; Kalim Belhacene, Adil Elagli, Philippe Supiot and Renato Froidevaux analyzed the data; Celine Vivien, Anthony Trezeibre, Pascal Dhulster, Philippe Supiot and Renato Froidevaux contributed reagents/materials/analysis tools; Kalim Belhacene, Adil Elagli, Philippe Supiot and Renato Froidevaux wrote the paper.

Conflicts of Interest: The authors declare no conflict of interest.

\section{References}

1. Hadd, A.G.; Raymond, D.E.; Halliwell, J.W.; Jacobson, S.C.; Ramsey, J.M. Microchip device for performing enzyme assays. Anal. Chem. 1997, 69, 3407-3412. [CrossRef] [PubMed]

2. Choi, J.Y.; Kim, Y.T.; Byun, J.Y.; Ahn, J.; Chung, S.; Gweon, D.G.; Kim, M.G.; Seo, T.S. An integrated allele-specific polymerase chain reaction-microarray chip for multiplex single nucleotide polymorphism typing. Lab Chip 2012, 12, 5146-5154. [CrossRef] [PubMed]

3. Sassolas, A.; Blum, L.J.; Bouvier, B.D.L. Immobilization strategies to develop enzymatic biosensors. Biotechnol. Adv. 2012, 30, 489-511. [CrossRef] [PubMed]

4. Ashraf, M.W.; Tayyaba, S.; Afzulpurkar, N. Micro Electromechanical Systems (MEMS) based microfluidic devices for biomedical applications. Int. J. Mol. Sci. 2011, 12, 3648-3704. [CrossRef] [PubMed]

5. Yoon, J.Y.; Kim, B. Lab-on-a-Chip pathogen sensors for food safety. Sensors 2012, 12, 10713-10741. [CrossRef] [PubMed]

6. Ogonczyk, D.; Jankowski, P.; Garstecki, P. Functionalization of polycarbonate with proteins; open-tubular enzymatic microreactors. Lab Chip 2012, 12, 2743-2748. [CrossRef] [PubMed]

7. Amorosi, C.; Mustin, C.; Frache, G.; Bertani, P.; Fahs, A.; Francius, G.; Toniazzo, V.; Ruch, D.; Ball, V.; Averous, L.; et al. Design of flexible free standing plasma polymer-based films as hosts for enzyme immobilization. J. Phys. Chem. C 2012, 116, 21356-21365. [CrossRef]

8. Heyries, K.A.; Marquette, C.A.; Blum, L.J. Straightforward protein immobilization on Sylgard 184 PDMS microarray surface. Langmuir 2007, 23, 4523-4527. [CrossRef] [PubMed] 
9. Sun, S.; Dong, L.; Xu, X.; Shen, S. Immobilization of $\beta$-galactosidase from Aspergillus Oryzae on Macroporous PloyGMA Newly Prepared. Int. J. Chem. 2010, 2. [CrossRef]

10. Elagli, A.; Belhacene, K.; Vivien, C.; Dhulster, P.; Froidevaux, R.; Supiot, P. Facile immobilization of enzyme by entrapment using a plasma-deposited organosilicon thin film. J. Mol. Catal. B Enzym. 2014, 110, 77-86. [CrossRef]

11. Heyse, P.; van Hoeck, A.; Roeffaers, M.B.J.; Raffin, J.P.; Steinbûchel, A.; Stoveken, T.; Lammertyn, J.; Verboven, P.; Jacobs, P.A.; Hofkens, J.; et al. Exploration of atmospheric pressure plasma nanofilm technology for straightforward bio-active coating deposition: Enzymes, plasmas and polymers, an elegant synergy. Plasma Process. Polym. 2011, 8, 965-974. [CrossRef]

12. Rabe, M.; Verdes, D.; Seeger, S. Understanding protein adsorption phenomena at solid surfaces. Adv. Colloid Interface Solid Sci. 2011, 1662, 87-106. [CrossRef] [PubMed]

13. Vasileva, N.; Iotov, V.; Ivanov, Y.; Godjevargova, T.; Kotia, N. Immobilization of -galactosidase on modified polypropilene membranes. Int. J. Biol. Macromol. 2012, 51, 710-719. [CrossRef] [PubMed]

14. Wu, Z.; Dong, M.; Lu, M.; Li, Z. Encapsulation of $\beta$-galactosidase from Aspergillus oryzae based on "fish-in-net" approach with molecular imprinting technique. J. Mol. Catal. B Enzym. 2010, 63, 75-80. [CrossRef]

15. Hanefel, U.; Gardossi, L.; Magner, E. Understanding enzyme immobilisation. Chem. Soc. Rev. 2009, 38, 453-468. [CrossRef] [PubMed]

16. Bocquet, B.; Bourzgui, N.E.; Guhel, Y.; Mille, V.; Vivien, C.; Supiot, P. Design of silicon-PPTMDS bio-MEMS by cold RPECVD. Proc. SPIE Microfluid. 2004, 5345, 118-129.

17. Mille, V.; Bourzgui, N.E.; Vivien, C.; Supiot, P.; Bocquet, B. ppTMDS as a new polymer technology for high throughput bio-MEMS design. J. Micromech. Microeng. 2008, 18, 125026. [CrossRef]

18. Abbas, A.; Treizebre, A.; Supiot, P.; Bourzgui, N.E.; Guillochon, D.; Vercaigne-Marko, D.; Bocquet, B. Cold plasma functionalized TeraHertz BioMEMS for enzyme reaction analysis. Biosens. Bioelectron. 2009, 25, 154-160. [CrossRef] [PubMed]

19. Supiot, P.; Vivien, C.; Blary, K.; Rouessac, V. Organosilicon polymers deposition by PECVD and RPECVD on micropatterned substrates. Chem. Vap. Depos. 2011, 17, 321-326. [CrossRef]

20. Urrutia, P.; Colinas, B.R.; Fernandez-Arrojo, L.; Ballesteros, A.O.; Wilson, L.; Illanes, A.; Plou, F.J. Detailed analysis of galactooligosaccharides synthesis with $\beta$-galactosidase from Aspergillus oryzae. J. Agric. Food Chem. 2013, 61, 1081-1087. [CrossRef] [PubMed]

21. Gaur, R.; Pant, H.; Jain, R.; Khare, S.K. Galacto-oligosaccharide synthesis by immobilized Aspergillus oryzae $\beta$-galactosidase. Food Chem. 2006, 97, 426-430. [CrossRef]

22. Gülec, H.; Gürdas, S.; Albayrak, N.; Mutlu, M. Immobilization of Aspergillus oryzae ß-Galactosidase on low-pressure plasma-modified cellulose acetate membrane using polyethyleneimine for production of galactooligosaccharide. Biotechnol. Bioprocess Eng. 2010, 15, 1006-1015. [CrossRef]

23. Gürdaş, S.; Güleç, H.A.; Mutlu, M. Immobilization of Aspergillus oryzae $\beta$-Galactosidase onto Duolite A568 Resin via Simple Adsorption Mechanism. Food Bioprocess Technol. 2012, 5, 904-911. [CrossRef]

24. Mariotti, M.P.; Yamanaka, H.; Araujo, A.R.; Trevisan, H.C. Hydrolysis of whey lactose by immobilized $\beta$-galactosidase. Braz. Arch Biol. Technol. 2008, 51, 1233-1240. [CrossRef]

25. Haubert, K.; Drier, T.; Beebe, D. PDMS bonding by means of a portable, low-cost corona system. Lab Chip 2006, 6, 1548-1549. [CrossRef] [PubMed]

26. Zhang, D.; Sun, Q.; Wadsworth, L.C. Mechanism of corona treatment on polyolefin films. Polym. Eng. Sci. 1998, 38, 965-970. [CrossRef]

27. Backer, R.W. Membrane Technology and Applications, 2nd ed.; John Wiley \& Son Ltd.: Hoboken, NJ, USA, 2004.

28. Seong, G.H.; Heo, J.; Crooks, R.M. Measurement of enzyme kinetics using a continuous-flow microfluidic system. Anal. Chem. 2003, 75, 3161-3167. [CrossRef] [PubMed]

29. Bayramoglu, G.; Tunali, Y.; Arica, M.Y. Immobilization of $\beta$-galactosidase onto magnetic poly(GMA-MMA) beads for hydrolysis of lactose in bed reactor. Catal. Commun. 2007, 8, 1094-1101. [CrossRef]

30. Batchelor, G.K. An Introduction to Fluid Dynamics; Cambridge University Press: Cambridge, UK, 1967; pp. 211-215.

31. Miller, C.C. The Stokes-Einstein Law for diffusion in solution. Proc. R. Soc. Lond. Ser. A 1924, 106, 724-749. [CrossRef]

32. Schilling, E.A.; Kamholz, A.E.; Yager, P. Optical measurement of transverse molecular diffusion in a microchannel. Anal. Chem. 2002, 74, 1798-1804. [CrossRef] [PubMed] 
33. Segel, I.H. Enzyme Kinetics: Behavior and Analysis of Rapid Equilibrium and Steady-State Enzyme Systems; Wiley Intersciences: New York, NY, USA, 1975; p. 957.

34. Colowick, S.P.; Kaplan, N.O. Methods in Enzymology. Immobilized Enzymes and Cells (Part C); Academic Press: San Diego, CA, USA, 1987; Volume 136.

35. Pallares, J.; Ferré, J.A. A simple model to predict mass transfer rates and kinetics of biochemical and biomedical Michaelis-Menten surface reactions. Int. J. Heat Mass Transf. 2015, 80, 192-198. [CrossRef]

36. Callebert, F.; Supiot, P.; Asfardjani, K.; Dessaut, O.; Gourmaud, P.; Dhamelicourt, P.; Laureyns, J. Cold remote nitrogen plasma polymerization from 1.1.3.3-tetramethyldisiloxane-oxygen mixture. J. Appl. Polym. Sci. 1994, 52, 1595-1606. [CrossRef]

37. Jambovane, S.; Duin, E.C.; Kim, S.-K.; Hong, J.W. Determination of kinetic parameters, $K_{\mathrm{m}}$ and $k_{\text {cat }}$, with a single experiment on a chip. Anal. Chem. 2009, 81, 3239-3245. [CrossRef] [PubMed]

38. Toepke, M.W.; Beebe, D. PDMS absorption of small molecules and consequences in microfluidic applications. Lab Chip 2006, 6, 1484-1486. [CrossRef] [PubMed]

39. Ghali, N.E.; Vivien, C.; Mutel, B.; Rives, A. Multilayer coating by plasma polymerization of TMDSO deposited on carbon steel: Synthesis and characterization. Surf. Coat. Technol. 2014, 259, 504-516. [CrossRef]

40. Rich, S.A.; Mille, V.; Vivien, C.; Godey, S.; Supiot, P. Kinetics of RPECVD Organosilicon Polymer Post-treatment in a $\mathrm{N}_{2} / \mathrm{O}_{2}$ Microwave Plasma Remote Afterglow. Plasma Process. Polym. 2010, 7, 775-784. [CrossRef]

(C) 2016 by the authors; licensee MDPI, Basel, Switzerland. This article is an open access article distributed under the terms and conditions of the Creative Commons Attribution (CC-BY) license (http://creativecommons.org/licenses/by/4.0/). 